\title{
Punjabi Adaptation of WHO's Global Physical Activity Questionnaire (GPAQ) in Gurumukhi Script: A Validity and Reliability Study
}

\author{
Harmandeep Singh ${ }^{1}$, Sukhdev Singh ${ }^{2}$, Amandeep Singh ${ }^{3}$ \\ ${ }^{1}$ Assistant Professor, Department of Physical Education, Apeejay College of Fine Arts, Jalandhar, Punjab, India, \\ ${ }^{2}$ Professor \& Head, Department of Physical Education (T) Guru Nanak Dev University, Amritsar, Punjab, India, \\ ${ }^{3}$ Assistant Professor, Department of Physical Education (T), Guru Nanak Dev University, Amritsar, Punjab, India
}

\begin{abstract}
Background: WHO's Global Physical Activity Questionnaire (GPAQ) has not yet been adapted in the Punjabi language. This study was aimed to adapt the GPAQ into the Punjabi language in Gurumukhi script and to make it useful for physical activity surveillance on Punjabi population.

Methods: We translated the GPAQ-English into Punjabi language (Gurumukhi script) using the forwardbackward translation technique. A total of 81 adult participants including staff and students having good command over Punjabi and English languages were conveniently recruited from Guru Nanak Dev University, Amritsar, Punjab, India. The validity of the adapted version was tested against the original English version of GPAQ by applying Spearman's rho. Test-retest reliability was tested by employing ICC coefficients.

Results: GPAQ-P demonstrated good validity for total PA $\left(\mathrm{r}_{\mathrm{s}}=0.877\right)$, work domain $\left(\mathrm{r}_{\mathrm{s}}=0.815\right)$, transport domain $\left(r_{\mathrm{s}}=0.876\right)$, and moderate intensity PA $\left(\mathrm{r}_{\mathrm{s}}=0.860\right)$; moderate validity for recreation domain $\left(\mathrm{r}_{\mathrm{s}}=\right.$ $0.643)$ and sitting time $\left(r_{s}=0.629\right)$; and low for vigorous intensity PA $\left(r_{s}=0.466\right)$. Moderate to excellent reliability was detected between two administration of GPAQ-P, excellent intraclass coefficients for total PA $(\mathrm{ICC}=0.918)$, work domain $(\mathrm{ICC}=0.943)$, transport domain $(\mathrm{ICC}=0.968)$, recreation domain $(\mathrm{ICC}=$ $0.952)$, and moderate intensity $(\mathrm{ICC}=0.956)$; good $\mathrm{ICC}$ for vigorous intensity $(\mathrm{ICC}=0.845)$ and moderate ICC for sitting time $(\mathrm{ICC}=0.704)$.
\end{abstract}

Conclusions: Punjabi adaptation of GPAQ in Gurumukhi script has good validity and reliability and it can be used for physical activity surveillance in Punjabi knowing population.

Keywords: Punjabi, GPAQ, validity, reliability, Physical activity, questionnaire, WHO

\section{Introduction}

The research area of Physical activity epidemiology in the Indian context is still barren. A very few studies have been accomplished concerning prevalence, patters and associated factors of physical activity in the Indian settings. ${ }^{1,2}$ Physical activity can be assessed among the populations using two approaches such as objective methods through the use of Accelerometers,

\section{Corresponding author:}

Amandeep Singh, $\mathrm{PhD}$

Email: prof_aman@yahoo.com
Pedometers, Doubly labeled water and heart rate monitors. ${ }^{3}$ The disadvantages associated with these methods are that these are relatively expensive and have less administration feasibility on larger populations. ${ }^{4}$ Alternatively, self-reporting approach is the most feasible methods to assess the physical activity levels in larger populations. ${ }^{5,6}$ But low validity and reliability of the questionnaire is the major limitation of this approach. Global Physical Activity Questionnaire is one of the widely used instrument for assessing the physical activity levels in epidemiological studies. ${ }^{7,8}$ It has been recommended by the WHO for its STEPwise Approach to Non-communicable Disease Risk Factor Surveillance 
(STEPS). ${ }^{7}$ Studies using GPAQ on Punjabi population are scarce. ${ }^{2}$ To the author's best knowledge, no Punjabi (Gurumukhi Script) adaptation of the GPAQ is available yet. Gurumukhi and Shahmukhi (Perso-Arabic) are two different scripts in which Punjabi is written. Gurumukhi script is used in Indian Punjab while Shahmukhi (PersoArabic) script is used in Pakistani Punjab. ${ }^{9}$ We have translated and adapted GPAQ into Gurumukhi script of Punjabi. The objective of this study was to establish the reliability and validity of the Punjabi version (Gurumukhi script) of WHO's Global Physical Activity Questionnaire.

\section{Material and Method}

\section{Sample}

As referred in previous studies, the ratio of 5 subjects per item was considered to finalize the sample. As GPAQ has a total of 16 items, it was assumed that a minimum 80 participants would be required for the study. ${ }^{10,11}$ Hence, by using the convenience sampling technique, a sample of 81 participants of age 18 to 64 years were recruited from Guru Nanak Dev University, Amritsar, Punjab, India. The sample consisted of 43 male and 39 females. Only those participants were included who can speak, read and write both Punjabi and English languages proficiently.

\section{Protocol}

Based on the methods adopted by previous similar studies, ${ }^{12,} 13$ the original English version of Global Physical Activity Questionnaire (GPAQ-English) was translated into the Punjabi language into 'Gurumukhi' script by the research team and then evaluated and back translated by three bilingual experts. Their disagreements were further discussed and a final consensus was made. Some more examples were inserted relevant to the local conditions to make the statements more intelligible to the respondents. Some terms of which no Punjabi version was available, were written in their original form in the Gurumukhi script. However, due consideration was given to maintain the actual concept of the statements. A pilot testing was done on a small sample of 20 subjects to elude any confusion or ambiguity in any of 16 items of the newly translated questionnaire.

\section{Data collection}

The original version and translated version of the GPAQ were distributed to the participants to fill in on day one and were instructed to continue their normal routine for a week ahead. On day eight, participants were again approached and asked to fill the same Punjabi version of GPAQ.

\section{Scoring}

Ainsworth's compendium of physical activity was used to assign the MET values to particular physical activities. ${ }^{14}$ For the estimation of energy cost, a value of 4 METs to moderate intensity activities and 8 METs was assigned to vigorous intensity activities. The METs $\mathrm{min} /$ week were computed using the following equation:

Minutes of activity/day X 7 days X MET level

\section{Data Analyses}

Descriptive statistics of MET scores derived from questionnaires were presented as mean, standard deviation and median. The concurrent validity of the GPAQ Punjabi version (filled on day 1) against the GPAQ English version was examined using Spearman's coefficient of correlation. Following the guidelines by Koo et al. ${ }^{15}$ on the selection of test-retest reliability analysis method, Intra-class correlation (ICC) with $95 \%$ confidence intervals was computed between the scores of first and second administrations of GPAQ-P. The results were considered significant at the 0.05 alpha level. 


\section{Findings}

Table 1: Descriptive figures of MET scores and sitting hours measured by GPAQ original and GPAQ-P on first and second administration

\begin{tabular}{|c|c|c|c|c|c|c|c|c|c|}
\hline \multirow{2}{*}{ Variable } & \multicolumn{3}{|c|}{ GPAQ (Original Version) } & \multicolumn{3}{|c|}{$\begin{array}{l}\text { GPAQ-P } \\
\text { (First administration) }\end{array}$} & \multicolumn{3}{|c|}{$\begin{array}{l}\text { GPAQ-P } \\
\text { (Second administration) }\end{array}$} \\
\hline & Mean & SD & Median & Mean & SD & Median & Mean & SD & Median \\
\hline $\begin{array}{l}\text { Work } \\
\text { domain } \\
\text { PA }\end{array}$ & 358.75 & 724.93 & 0 & 325.86 & 682.62 & 0 & 422.13 & 688.77 & 180 \\
\hline $\begin{array}{l}\text { Transport } \\
\text { domain } \\
\text { PA }\end{array}$ & 418.50 & 721.73 & 0 & 459.63 & 693.59 & 0 & 524.36 & 749.63 & 130 \\
\hline $\begin{array}{l}\text { Recreation } \\
\text { domain } \\
\text { PA }\end{array}$ & 168.25 & 449.98 & 0 & 360.25 & 602.51 & 0 & 423.88 & 364.38 & 170 \\
\hline $\begin{array}{l}\text { Moderate } \\
\text { intensity } \\
\text { PA }\end{array}$ & 868 & 1162.33 & 290 & 827.13 & 891.95 & 480 & 911.63 & 869.88 & 790 \\
\hline $\begin{array}{l}\text { Vigorous } \\
\text { intensity } \\
\text { PA }\end{array}$ & 85.75 & 301.53 & 0 & 300.36 & 498.86 & 0 & 446.13 & 545.68 & 300 \\
\hline Total PA & 945.50 & 1126.61 & 400 & 1146.25 & 1077.52 & 970 & 1370.38 & 1116.36 & 1240 \\
\hline $\begin{array}{l}\text { Sitting } \\
\text { time } \\
\text { (hours/ } \\
\text { day) }\end{array}$ & 8.53 & 2.82 & 8 & 8.03 & 2.99 & 8 & 8.40 & 2.75 & 8 \\
\hline
\end{tabular}

$G P A Q=$ Global Physical Activity Questionnaire

GPAQ-P = Global Physical Activity Questionnaire-Punjabi

$P A=$ Physical Activity

$S D=$ Standard deviation 
Table 2: Spearman's rho between original version of GPAQ and Punjabi (Gurumukhi script) version of GPAQ

\begin{tabular}{|l|l|l|l|l|l|l|}
\hline \multirow{2}{*}{ GPAQ-P (MET-min/week) } & \multicolumn{2}{|l|}{ Males (N=43) } & \multicolumn{2}{l|}{ Females (N=39) } & \multicolumn{2}{l|}{ Both genders (N=81) } \\
\cline { 2 - 7 } & $\mathbf{r}_{\mathrm{s}}$ & Sig. & $\mathbf{r}_{\mathrm{s}}$ & Sig. & \multicolumn{2}{l|}{$\mathbf{r}_{\mathrm{s}}$} \\
\hline Work domain PA & 0.751 & $0.001^{*}$ & 0.861 & $0.001^{*}$ & 0.815 & $0.001^{*}$ \\
\hline Transport domain PA & 0.893 & $0.001^{*}$ & 0.853 & $0.001^{*}$ & 0.876 & $0.001^{*}$ \\
\hline Recreation domain PA & 0.538 & $0.001^{*}$ & 0.746 & $0.001^{*}$ & 0.643 & $0.001^{*}$ \\
\hline Moderate intensity PA & 0.811 & $0.001^{*}$ & 0.887 & $0.001^{*}$ & 0.860 & $0.001^{*}$ \\
\hline Vigorous intensity PA & 0.500 & $0.001^{*}$ & 0.444 & $0.001^{*}$ & 0.466 & $0.001^{*}$ \\
\hline Total PA & 0.843 & $0.001^{*}$ & 0.910 & $0.001^{*}$ & 0.877 & $0.001^{*}$ \\
\hline Sitting time & 0.491 & $0.001^{*}$ & 0.744 & $0.001^{*}$ & 0.629 & $0.001^{*}$ \\
\hline
\end{tabular}

$r_{s}=$ Spearman's correlation of coefficient

MET $=$ Metabolic equivalent of task

Table 2 demonstrates the results of concurrent validity of GPAQ-P against the original GPAQ. Spearman's correlation of coefficient was run to examine the correlation between MET scores of different domains, intensities and total PA alongwith sitting time hours/day. Analyses revealed good correlation in all categories and both genders ranging from .466 to $.877(\mathrm{p}<.05)$. In a combined sample of both genders, maximum and minimum correlations were found in total
PA $\left(\mathrm{r}_{\mathrm{s}}=.877\right)$ and vigorous PA $\left(\mathrm{r}_{\mathrm{s}}=.466\right)$ respectively. Meanwhile, high correlations were noticed in Moderate

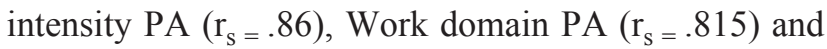
transport domain PA $\left(\mathrm{r}_{\mathrm{s}}=.876\right)$ with original GPAQ scores. Low to moderate correlations were observed in vigorous intensity $\mathrm{PA}\left(\mathrm{r}_{\mathrm{s}}=.466\right)$ and recreation domain PA $\left(r_{\mathrm{s}}=.629\right)$. The correlation for sitting time was also acceptable $\left(r_{s}=.629\right)$. In this case, scores of females depicted better correlation $\left(\mathrm{r}_{\mathrm{s}}=.744\right)$ than males $\left(\mathrm{r}_{\mathrm{s}}=.491\right)$ in sitting time.

Table 3: Reliability of GPAQ-P based on ICC coefficients

\begin{tabular}{|c|c|c|c|}
\hline \multirow{2}{*}{ GPAQ-P (MET-min/week) } & \multicolumn{3}{|c|}{ ICC (95\% Confidence intervals) } \\
\hline & Males & Females & Overall \\
\hline Work domain PA & $0.917(0.852-0.954)$ & $0.967(0.939-0.983)$ & $0.943(0.912-0.963)$ \\
\hline Transport domain PA & $0.964(0.934-980)$ & $0.979(0.960-0.989)$ & $0.968(0.968-0.951)$ \\
\hline Recreation domain PA & $0.905(0.832-.947)$ & $0.974(0.952-0.987)$ & $0.952(0.927-0.969)$ \\
\hline Moderate intensity PA & $0.952(0.913-0.974)$ & $0.962(0.929-0.980)$ & $0.956(0.932-0.971)$ \\
\hline Vigorous intensity PA & $0.791(0.648-0.881)$ & $0.902(0.821-0.948)$ & $0.845(0.77-0.898)$ \\
\hline Total PA & $0.897(0.819-0.943)$ & $0.944(0.896-0.971)$ & $0.918(0.875-0.946)$ \\
\hline Sitting time & $0.59(0.357-0.754)$ & $0.782(0.621-0.936)$ & $0.704(0.575-0.799)$ \\
\hline
\end{tabular}

ICC $=$ Intra class correlation 
Table 3 shows the results of reliability analyses of scores of GPAQ-P. Significant intra class correlations were detected among all categories of GPAQ-P. Excellent correlations were observed for work domain PA $(\mathrm{ICC}=0.943, \mathrm{CI}=0.912-0.963)$, transport domain $\mathrm{PA}(\mathrm{ICC}=0.968, \mathrm{CI}=0.951-0.979)$, recreation domain PA $(\mathrm{ICC}=0.952, \mathrm{CI}=0.927-0.969)$, moderate intensity PA $(\mathrm{ICC}=0.956, \mathrm{CI}=0.932-0.971)$ and total PA scores $(\mathrm{ICC}=.918, \mathrm{CI}=0.875-0.946)$. A slightly less correlation was found for vigorous intensity PA (ICC $=0.845, \mathrm{CI}=0.77-0.898)$ but the correlation was still high though not excellent. Meanwhile, a moderate correlation was found for sitting hours (ICC $=0.704$, CI $=0.575-0.799)$. Similar to validity analyses, females showed better reliability than males in each category.

\section{Discussion}

The study was intended to develop a Punjabi version (Gurumukhi Script) of Global Physical Activity Questionnaire (GPAQ) which is an official instrument of WHO for physical activity surveillance in large population settings. The original version of GPAQ is in English language and Roman script. ${ }^{7}$ GPAQ is also part of WHO's STEPwise approach to non-communicable disease risk factor surveillance. ${ }^{7,8}$ The current study has focused on the Punjabi language of northern India, in which GPAQ has not been translated yet. In this regard, taking into consideration the high need for Punjabi adaptation of GPAQ, a Punjabi translation of GPAQ was done by utilizing the protocol mentioned in the material and methods section. The results revealed significant validity and reliability of the Punjabi version of GPAQ. Excellent validity was observed in total PA scores, work domain, transport PA and moderate intensity scores except for vigorous intensity and recreation PA that showed low and moderate validity respectively. Furthermore, females showed higher correlations than males in terms of validity. Similar results were observed by Mumu et al. ${ }^{8}$ while validating GPAQ in Bangladeshi population. Contrarily, another study on the French version of GPAQ demonstrated limited though acceptable validity and reliability. ${ }^{12}$ In a comprehensive study in nine countries, GPAQ had shown poor validity and reliability. ${ }^{16}$ In the same study, sitting time was poorly and insignificantly related to pedometer data. However, in our study, sitting time was also found to have acceptable validity and reliability in the overall sample. The reason for those poor results may be that they used the original English version of GPAQ in those populations whose native language is not English. The same study has recommended local adaptations of the instrument to make it more intelligible to the non-English speakers. Another study on the Brazilian population observed acceptable reliability but limited validity. ${ }^{17}$ Our results showed high reliability in all PA domains and intensities whereas as reported by Bull et al. ${ }^{16}$ work domain has shown higher reliability than recreation and transport domains in the reliability studies of Bangladeshi, Chinese, Ethiopian, Indonesian, South African, Japanese, and Taiwanese versions of GPAQ. A review of literature led by Matthews ${ }^{18}$ reported that the GPAQ has similar validity and reliability to other physical activity questionnaires such as the IPAQ, Madras Diabetes Research FoundationPhysical Activity Questionnaire (MPAQ), Total Energy Expenditure Questionnaire (TEEQ), etc. In Punjabi context, International Physical Activity Questionnaire short form (IPAQ-SF) has been adapted in the Punjabi language by Shenoy et al. ${ }^{13}$ They found Spearman's coefficient of 0.994, signifying excellent concurrent validity of IPAQ-SF Punjabi version. They found excellent validity for moderate and vigorous intensities. However, the major limitation of IPAQ-SF is that it does not measure domain-specific physical activity whereas GPAQ has the advantage of being short and producing domain-specific PA data. Although the adapted Punjabi version of GPAQ has shown good validity and reliability, refinement is still required to standardize it by using more rigorous methods.

\section{Limitations}

At first, the sample size was small and subjects were not included from all age groups, socioeconomic statuses, and both urban and rural populations. Increased sample size may have produced more truthful results. Second, the validity was not tested against any objective measure such as accelerometers, pedometers or heart rate monitors which provide more accurate data on physical activity than self-report questionnaires. Third, recall bias may have its effects on the mindset of subjects.

\section{Suggestions for future research}

This is the first attempt to adapt the WHO's GPAQ instrument in Punjabi for surveying physical activity in 
larger populations. More studies of this kind with greater sample size are required to be carried out at local level to validate the adapted version.

More robust methods for establishing validity such as accelerometery, pedometery or heart rate monitoring may be used.

International Physical Activity Questionnaire long form (IPAQ-LF) is another widely used questionnaire for population surveys of PA. Concurrent validity of GPAQ-P against IPAQ-long form may be assessed in a further study.

Apart from Gurumukhi script, Punjabi is also being written in 'Shahmukhi' (Perso-Arabic) script in Pakistani Punjab, so a Punjabi translation in 'Shahmukhi' (PersoArabic) script is also required to be done.

\section{Conclusion}

The Punjabi version of WHO's GPAQ in Gurumukhi script has acceptable validity and reliability and can be used for physical activity surveillance of Punjabi speaking population. It would be easy to understand for Punjabi speakers as it is enriched with local and simplified examples of work, transport and recreation domains, and PA intensities.

Conflict of Interest: No conflict of interests to declare.

Source of Funding: The study was funded by University Grants Commission (UGC) as Senior Research Fellowship for PhD study to the first author of this paper.

Acknowledgement: The authors would like to thank the translators for their scholarly input to the study and also would like to thank the participants for participating the study and their timely cooperation.

Ethical Approval: The study was approved by ethical committee of Faculty of Physical Education (T), Guru Nanak Dev University, Amritsar, Punjab, India.

\section{References}

1. Singh H, Singh S. Prevalence, patterns and associated factors of Physical Activity in Indian University students. European Journal of Physical Education and Sport Science. 2017 Sep 6.
2. Thakur JS, Jeet G, Pal A, Singh S, Singh A, Deepti SS, Lal M, Gupta S, Prasad R, Jain S, Saran R. Profile of risk factors for non-communicable diseases in Punjab, Northern India: Results of a state-wide STEPS survey. PLoS One. 2016 Jul 7;11(7): e0157705.

3. Castillo-Retamal M, Hinckson EA. Measuring physical activity and sedentary behaviour at work: a review. Work. 2011 Jan 1;40(4):345-57.

4. Leinonen AM, Ahola R, Kulmala J, Hakonen H, Vähä-Ypyä H, Herzig KH, Auvinen J, KeinänenKiukaanniemi S, Sievänen $H$, Tammelin TH, Korpelainen R. Measuring physical activity in free-living conditions-comparison of three accelerometry-based methods. Frontiers in physiology. 2017 Jan 10; 7:681.

5. Sylvia LG, Bernstein EE, Hubbard JL, Keating L, Anderson EJ. Practical guide to measuring physical activity. Journal of the Academy of Nutrition and Dietetics. 2014 Feb 1;114(2):199-208.

6. Sallis JF. Measuring physical activity: practical approaches for program evaluation in Native American communities. Journal of public health management and practice: JPHMP. 2010 Sep;16(5):404.

7. Armstrong, Timothy, and Fiona Bull. "Development of the world health organization global physical activity questionnaire (GPAQ).” Journal of Public Health 14.2 (2006): 66-70.

8. Mumu SJ, Ali L, Barnett A, Merom D. Validity of the global physical activity questionnaire (GPAQ) in Bangladesh. BMC public health. 2017 Dec;17(1):650.

9. Indo-Aryan languages. Retrieved from https:// en.wikipedia.org/wiki/Indo-Aryan_languages.

10. Anthoine E, Moret L, Regnault A, Sébille V, Hardouin JB. Sample size used to validate a scale: a review of publications on newly-developed patient reported outcomes measures. Health and quality of life outcomes. 2014 Dec;12(1):2.

11. Rivière F, Widad FZ, Speyer E, Erpelding ML, Escalon H, Vuillemin A. Reliability and validity of the French version of the global physical activity questionnaire. Journal of sport and health science. 2018 Jul 1;7(3):339-45.

12. Chu AH, Moy FM. Reliability and validity of the Malay International Physical Activity Questionnaire (IPAQ-M) among a Malay population in Malaysia. 
Asia Pacific Journal of Public Health. 2015 Mar;27(2):NP2381-9.

13. Shenoy S, Chawla JK, Sandhu JS. Validation of short international physical activity questionnaire Punjabi version in India. Saudi Journal of Sports Medicine. 2014 Jul 1;14(2):77.

14. Ainsworth BE, Haskell WL, Whitt MC, Irwin ML, Swartz AM, Strath SJ, O Brien WL, Bassett DR, Schmitz KH, Emplaincourt PO, Jacobs DR. Compendium of physical activities: an update of activity codes and MET intensities. Medicine and science in sports and exercise. 2000 Sep 1;32(9; SUPP/1): S498-504.

15. Koo TK, Li MY. A guideline of selecting and reporting intraclass correlation coefficients for reliability research. Journal of chiropractic medicine. 2016 Jun 1;15(2):155-63.

16. Bull FC, Maslin TS, Armstrong T. Global physical activity questionnaire (GPAQ): nine country reliability and validity study. Journal of Physical Activity and health. 2009 Nov 1;6(6):790-804.

17. Martins RC, Blumenberg C, da Silva IC. Reliability and concurrent validity of the Global Physical Activity Questionnaire in adults from a Brazilian rural área. Revista Brasileira de Atividade Física \& Saúde. 2018 Aug 31; 23:1-6.

18. Matthews KM. Reliability and validity of the global physical activity questionnaire (GPAQ) and its utility: a review of the literature (Doctoral dissertation). 